Revista Letras,

Curitiba, n. 94 jun./dez. 2016. ISSN 2236-0999

\section{Iracema vota. Ficção, Política e História em José de}

Alencar

\author{
Iracema votes. Fiction, Politics, and History in the works \\ of José de Alencar
}

Carlos Alberto Medeiros Lima *

Neste artigo, comparam-se as percepções acerca da sociedade e da história brasileiras contidas em um ensaio político escrito por José de Alencar - Systema representativo (1868) - e em seus romances, de acordo com análises destes últimos presentes na história literária. O conceito de representação legível no ensaio político ligava-se a uma pregação do Autor em favor da introdução da representação proporcional no Império, e permite compreender as visões de José de Alencar a respeito dos ambientes locais, "exóticos”, de um lado, e do projeto civilizador, de outro lado.

Palavras-chave: José de Alencar; política Imperial; ficção e história.

ABSTRACT:

This article compares the perceptions about Brazilian society and history contained in a political essay and in the novels written by the Brazilian romantic novelist José de Alencar. The novels are approached through some representative works on Literary History. The concept of representation present in the political essay, Systema representativo (1868), was part of a campaign for the introduction of proportional representation in the country, and it allows the reader to understand the connection between the Author's opinions on the local, "exotic", Brazilian worlds, on the one hand, and on the civilizing project, on the other hand.

Keywords: José de Alencar; Imperial politics; fiction and history.

${ }^{\star}$ UFPR/CNPQ. O autor agradece as sugestões dos revisores da Revista Letras. 
Lima, C. A. M. Iracema vota. Fiç̧ão, Política e História em José de Alencar.

A matéria do romance é o passado histórico, ainda vivo, sujeito a revisões, inconfundível com o passado mítico, cristalizado, imutável. O romance não comporta heróis, no sentido clássico, mas seres humanos, igualmente capazes de atos heroicos, determinados por motivos vis, e de ações condenáveis movidas por sentimentos nobres

(WEINHARDt, 1994, p. 50).

Revista Letras, Curitiba, n. 94 p. 142-155, jun./dez. 2016. ISSN 2236-0999 

Weinhardt quanto ao uso de um trecho de um de seus fundamentais artigos, este trabalho parte de algumas questões postas pela epígrafe. Ele vem da exposição feita por ela sobre as concepções de Bakhtin a respeito do romance histórico, confrontado com a epopeia.

A ideia de passado histórico ainda vivo é fundamental para compreender aspectos centrais do romance de José de Alencar. Defende-se aqui que levar em consideração sua obra política leva a pensar que esse passado era, para o Autor, vivo a ponto de fornecer estratégias e chaves para a detecção de instrumentos de canalização de energias transformadoras.

Para argumentar nessa direção, as presentes notas confrontam uma leitura do Systema Representativo, de José de Alencar (1868), com alguns aspectos enfatizados pela crítica e pela História Literária quanto à ficção alencariana. ${ }^{1} \mathrm{Na}$

1 A substituição do gabinete liberal (progressista) de Zacarias de Góis pelo ultraconservador, de Itaboraí, em 1868, acirrou de uma maneira que não tinha precedentes o debate sobre fórmulas eleitorais, assim como a crítica ao poder pessoal do monarca (BOSI, 2004, p. 38, 42; SILVA, 2005, p. 18). Antes, de 1864 a 1868, o Segundo Reinado tivera a maior instabilidade ministerial de sua história, o que passou também por grande agitação entre os progressistas, divididos entre dissidentes e históricos, e pela introdução da questão da escravidão na Fala do Trono de 1867. Tratava-se do fim da "conciliação" inaugurada em 1853, e no próprio ano de 1868 assistiu-se à formação do grupo dos liberais radicais (CARvalho, 2009, p. 23, 25, 27). Em 1868-1870, após, portanto, a escrita do livro aqui examinado, Alencar foi ministro da Justiça, tendo, antes, passa- 
Lima, C. A. M. Iracema vota. Ficção, Política e História em José de Alencar.

Revista Letras,

Curitiba, n. 94 p. 142-155, jun./dez. 2016. ISSN 2236-0999 crítica, importam para o presente trabalho especialmente dois aspectos. O primeiro é uma relativa disjunção apontada no romance, segundo a qual o elemento local, específico e identitário ficava acoplado de modo às vezes paradoxal a convenções e recursos universais da produção romântica, ou então a uma posição do narrador muito pouco ligada a qualquer desses mundos locais. O segundo liga-se a uma preocupação decisiva detectada em Alencar com o problema do vínculo, do liame social.

Uma primeira indicação da crítica é a de que operava no romance alencariano a apropriação de um mundo rural a que não mais pertenciam o Autor, o narrador e o leitor (GIL, 2010, p. 135). De fato, isso estaria ligado à própria natureza do romance. Em compasso semelhante, e segundo Antonio Candido, ao mesmo tempo que Alencar escrevia para a terra, não era exatamente a ela que fazia referência. $\mathrm{O}$ indianismo, por exemplo, seria marcado pela simultaneidade da "matéria local" e da mobilização de tradições literárias mais amadurecidas (fora do Império). Isso constituiria uma "dupla fidelidade" (GIL, 2011, p. 54, 57), manifestando também o caráter de "gênero inter-nacional" do romance (vASCONCELOS, 2012, p. 272, 289).

Marcelo Peloggio faz referência a essas tensões, em vista do modo como Alencar via o Brasil. O sentido era o de "nacionalizar" o país. Fazê-lo, no entanto, não significava apontar-lhe uma identidade. Antes, tratava-se de civilizá-lo, levando em conta, embora, que tudo devia ocorrer de um modo que não o descaracterizasse no que tinha de "mais caro e valioso: sua natureza, sua gente" (PELOGGIO, 2006, p. 11). As tensões, segundo essa visão, eram na verdade múltiplas: "nacionalizar" implicaria uma superação de multiplicidades de corte social ou regional ao mesmo tempo que essa multiplicidade era de alguma forma comemorada; "nacionalizar" poderia voltar-se para o exterior, implicando a proclamação de uma particularidade nacional frente às outras nações, mas também para o seu inverso, significando "civilizar" o país até a obtenção de um patamar mínimo de uniformidade de comportamentos, patamar este ditado por uma concepção universal a respeito de que costumes seriam adequados à sociedade.

José Maurício Gomes de Almeida faz referência a situações e personagens buscados no repertório mítico das literaturas europeias, com o que o centro de suas preocupações não estaria no exotismo, nem na particularidade regional (GIL, 2010, p. 137). Os tipos locais, diz Fernando Gil, seguindo Antonio Candido, mais que manifestar a nacionalidade, exemplificariam o caráter multiforme desta última (GIL, 2011, p. 55). De alguma forma, mantinha-se uma separação entre os múltiplos tipos locais e um tipo nacional em verdade não explicitado.

Antonio Candido aponta os "vícios habituais" do regionalismo como gênero. Enfatiza o pitoresco superficial e a noção recorrente a respeito da pureza rural contraposta ao artificialismo da cidade (CANDido, 1999, p. 46). Escreve também sobre o "nacionalismo literário" buscando o "exotismo" regionalista

do nove anos emitindo pareceres na secretaria de justiça (BLAKe, 1970, p. 74). 
Lima, C. A. M. Iracema vota. Fiç̧ão, Política e História em José de Alencar.
(GIL, 2011, p. 57). É difícil, mas necessário, conjugar a imagem de integração personagem-espaço presente n'O sertanejo (GIL, 2010, p. 138) com a das "fezes locais" a serem expurgadas da representação política pela "nacionalização", desagradável noção que será rastreada adiante nos textos políticos de Alencar. Isso é indicado pelo fato de autor e narrador mostrarem francamente não pertencerem a um mundo do qual insistentemente se apropriavam. Alencar, por exemplo, teria escrito O gaúcho sem jamais ter visitado o Rio Grande do Sul (BLAke, 1970, p. 76).

Além da disjunção, a crítica costuma enfatizar que o elemento efetivamente comemorado era o vínculo entre personagens históricos, mais que as características desses personagens. Neste trabalho, dá-se a isso o nome de visão relacional do passado, o que, no tocante aos romances, pode ser exemplificado com a ênfase dada por Bosi aos atos dos senhores da hierarquia social de renomeação dos subalternos que a eles se entregavam ritualmente (воsI, 1992, p. 177). Põe acento na "entrega [...] incondicional [...] de corpo e alma". Avança ainda em afirmar um "complexo sacrificial" em Alencar, segundo o qual a nobreza dos fracos dependeria de sua autoimolação (Bosı, 1992, p. 178). Alencar comemorava a entrega, jamais a indianidade. Comemorar a entrega significava encontrar no passado algo bem mais precioso que uma identidade. Implicava encontrar nos tempos idos uma propensão ao vínculo. Déborah Scheidt indica que o "esforço" de Alencar se dirigia para retratar a zona de contato "entre culturas e espaços geográficos antagônicos” (scheidT, 2010, p. 337). Sandra Vasconcelos ressalta o "mito de fundação, forjado na união dos povos" presente no romance alencariano, mesmo que o "olhar mais atento" não possa deixar de reconhecer grande dose de violência nos processos (vasconcelos, 2012, p. 272). De modo mais direto, Celeste Sousa apontou apego alencariano à ideia de que o brasileiro seria filho da miscigenação racial e cultural entre um português e uma índia (sousA, 2009, p. 39).

Essa visão mais relacional que identitária do romance prossegue com o trabalho de Eduardo Vieira Martins, segundo o qual tinham vigência no trabalho alencariano, especialmente n'O sertanejo, duas hierarquias: a social e aquela estabelecida pela valorização da proximidade frente à natureza (MARTINs, 1997, p. 67). Essa visão da hierarquia é relacional, ressaltando sua capacidade de integrar e criar vínculos legitimados, sobretudo como efeito da superposição de hierarquias de sentido inverso.

Essa passagem breve pela crítica não pôde fazer justiça aos trabalhos citados e nem ressaltar eventuais diferenças interpretativas. Mas, de posse dessas duas noções - a da disjunção entre universos e a da centralidade nos vínculos -, podese passar para O Sistema Representativo. Ponto essencial deste trabalho de Alencar é o da representação proporcional, em oposição aos "círculos" (distritos) imperiais. À partida, ligava isso à questão da representação das minorias (ALENCAR, 1991, p. 3; a ortografia foi atualizada nas citações do texto de Alencar), segundo 
Lima, C. A. M. Iracema vota. Ficção, Política e História em José de Alencar. o conceito que tinha a respeito daquela. Constituiria o "meio de concentrar a vontade nacional para a organização do poder público" (ALencaR, 1991, p. 9). Ela, portanto, era em Alencar um meio de reunir vontades e energias na direção de compor governos. Consistiria em algo mais englobante que excludente.

É grande a distância entre essa percepção e a formulação singela de Marshall, formulada no século XX: "direito de participar no exercício do poder político, como um membro de um organismo investido da autoridade política ou como um eleitor dos membros de tal organismo" (MARshall, 1967, p. 63). $\mathrm{O}$ foco muda. O que Alencar buscava era um método para sintetizar as diversas vontades presentes no país e torná-las projeto, programa. Em Marshall, o foco estava nos direitos. Assim, no escritor brasileiro do século xix, "o voto não é, como pretendem muitos, um direito político". Mais que isso, é uma "fração da soberania" (ALENCAR, 1991, p. 75), ou então o "elemento da soberania" (alencar, 1991, p. 9). O centro do raciocínio, portanto, estava em uma visão quase redistributiva, centrada em compartilhamento e englobamento.

A formulação alencariana girava ao redor daquilo chamado no livro estudado de "nacionalização", ou, referindo-se à Grécia Clássica, de "transfusão dos espíritos para a gestação da substância nacional” (ALENCAR, 1991, p. 30). O voto, quando praticado de modo apropriado, "longe de exprimir o pensamento especial e próprio do votante, [...] traduz a opinião geral sob cuja influência é proferido" (alencar, 1991, p. 31). Por “contágio moral”, forma-se uma “opinião complexa que é então a consciência coletiva” (alencar, 1991, p. 32). O que buscava era, através de uma cadeia de vínculos, formar uma "vontade" que "não pertence ao número superior, mas sim à totalidade” (ALENCAR, 1991, p. 32). Essa vontade devia corporificar-se em "partidos nacionais", uma "influência geral", apta a abranger "toda a esfera e capaz de sufocar as opostas tendências locais". Fora dessa esfera, a política "desnacionaliza-se" (ALencar, 1991, p. 58).

A "soma das paixões locais não constitui a opinião nacional". Esta última seria a "consubstanciação da grande alma do país" (ALEnCAR, 1991, p. 112), devendo a representação política ao mesmo tempo exprimir e ajudar a construir isso. O objetivo seria "dar a todas as opiniões formadas no país um órgão no parlamento, e portanto uma intervenção no governo” (ALENCAR, 1991, p. 120). Isso incentivava Alencar, inclusive, a posicionar-se em favor da publicidade do voto. Resultaria disso a "Atenas moderna": "a nata do povo no parlamento" (ALENCAR, 1991, p. 44). Assim, montada a "representação integral" (ALENCAR, 1991, p. 177), seria possível a "civilização completa do povo" (ALENCAR, 1991, p. 180).

A "representação", assim, não remetia a um direito, nem a pactos, nem ainda à capacidade de escolha ou à vontade individual. Tratava-se apenas de uma das formas de "delegação da soberania", aquela "considerada em sua generalidade". Quando tivesse seu foco no cidadão, aquela delegação deveria ser chamada "voto". Essa distinção teórica entre voto e representação é importante, e permite 
Lima, C. A. M. Iracema vota. Fiç̧ão, Política e História em José de Alencar. a Alencar tratar como representativos diversos elementos que não julgaríamos enquanto tais. Havia um foco organicista irrefutável nessas distinções. Assim, conforme escreveu em um "Esboço da nova lei eleitoral" anexado ao livro, "A representação nacional, além do Imperador, representante perpétuo e dinástico, e do regente que o substitui, se compõe de deputados e senadores" (aLENCAR, 1991, p. 185). Aquele que nasceu imperador era tão representante quanto os parlamentares, pois sob essa ótica o representado era a "generalidade”. É verdade que o Autor citava, à sua maneira, a Constituição de 1824. Mas inegavelmente acrescentava ênfase à semelhança entre deputados, senadores, imperador e regentes.

O movimento inverso também era executado, com o Autor movendo-se do registro organicista para uma visão mais individualista. Embora se escreva sobre o "exotismo" ou a "heroicização" incidente na percepção alencariana acerca dos diversos grupos constitutivos da sociedade brasileira, sua visão de Brasil podia circunscrever-se às categorias organizadas ao redor de um projeto civilizador, autoritário, universalizante e inteiramente despido de exotismo, como era o projeto que historiadores atribuem aos grupos políticos oitocentistas brasileiros. Assim, ao invés da particularidade, da diferença, punha em jogo a perspectiva da reforma dos costumes, impondo progresso forçado e usando de modo autoritário categorias universais, como um modelo de comportamento. Isso pode auxiliar a compreender a passagem do organicismo ao individualismo da distinção representação/voto. Afinal, o projeto de todos os civilizadores era chegar a uma nação de pequenos franceses, ou pequenos britânicos.

O reformismo dos costumes aparecia com força em diversos momentos. Assim, para Alencar, a democracia devia ser graduada ao "estado de instrução e moralidade do povo". Ela podia ser mais ampla, como nos casos nos quais os representantes tivessem atribuições restritas e de prazo curto, tendo o contrário sido aquilo que a restringia. Um povo instruído e moral poderia ter tipos mais próximos da primeira situação. A segunda seria indispensável na situação inversa (ALENCAR, 1991, p. 10). Mas as oscilações entre identidade e modelos universais nunca se dissipavam. Entendeu que as formas de governo e a divisão dos poderes variariam conforme a "índole do povo" (aLENCAR, 1991, p. 12), o que podia significar tanto o "estado de instrução" mencionado acima e referido ao projeto civilizador, quanto a particularidade de uma história própria do país.

Às vezes, prometia por acento mais nítido nas diferenças, como em um momento no qual distinguiu teoricamente indivíduo e povo (ALENCAR, 1991, p. 11). Mas logo recuava e tratava o segundo termo como mais articulado à igualdade civil que à particularização de uma história nacional. Assim, a oposição que enxergava, e que considerava questão não resolvida pela ciência, era aquela entre independência individual e a igualdade democrática, e não aquela entre a vontade individual e uma particularidade nacional enxergada em termos holísticos. Apesar dessas ambivalências, prevalecia uma forte ênfase na reforma dos costumes. O Parlamento, por exemplo, deveria abrigar "os órgãos das grandes 
Lima, C. A. M. Iracema vota. Ficção, Política e História em José de Alencar. ideias civilizadoras" (ALENCAR, 1991, p. 54).

Romantismo político, portanto, não pode ser visto como uma espécie de passadismo, do que resultava o fato de o registro organicista aparecer e desaparecer repetidamente no texto. Alencar não idealizava nem o passado nacional, nem a democracia dos antigos. Quanto a esta, sustentava que "o homem era exclusivamente cidadão, dava-se todo á cousa pública; não tinha a domesticidade que o distraísse" (alencar, 1991, p. 35). Em outras palavras, inexistia a distinção entre público e privado que a democracia representativa passou a permitir no mundo moderno. Sua concepção de liberdade era, nitidamente, a dos modernos. Uma variante dessa crítica à democracia dos antigos era a rejeição da "delegação" por Alencar, que a via em alguns países em seu próprio tempo. Com ela, e dada a vastidão dos mesmos países, os supostos representantes tornavam-se delegados de apenas uma parte de sua nação, parte essa que, assim, exercia "despotismo" sobre as outras (ALENCAR, 1991, p. 37). Exemplificou com "comícios paroquiais" que quase sempre elegiam "comissários da maioria" apenas entre os "sectários da conservação do trabalho escravo” (ALENCAR, 1991, p. 38), impondo a todos essa conservação. Outra variante, ainda, da rejeição de parâmetros do mundo clássico antigo radicava na recusa da antiga teoria das formas de governo, que assimilava à teorização do mero amontoamento de déspotas de diferentes dimensões (ALENCAR, 1991, p. 33).

O trecho sobre os comícios paroquiais mostra que Alencar associava a política local ao mandato imperativo. Julgava, portanto, que a dinâmica da vida local travaria um projeto civilizador. Era reiterada a ideia de que gatilhos institucionais deveriam fazer com que votantes tivessem suas vistas voltadas para fora do estreito mundo local, o que é à primeira vista difícil de conciliar com o problema dos vínculos, obsessão alencariana a que já se fez referência e de que se voltará a tratar. Por ora, remeta-se ao fato de que Alencar relaciona esse problema do "vínculo" entre representante e representado a John Stuart Mill (aLencar, 1991, p. 60), dado cuja importância se escora na ênfase que percorre todo o livro na necessidade da representação proporcional.

Esse vínculo entre representante e representado não poderia ser visto por ele como uma espécie de gaiola local, desnacionalizada e incivilizada, que prenderia o parlamentar às estreitas vistas dos paroquianos, amarrado que estaria o primeiro ao mandato imperativo. Assim, ele deveria ser "moral", sem jamais ameaçar a "plena liberdade de pensamento" do deputado (alencar, 1991, p. 66). Essa questão do "vínculo moral" tem enorme importância. Faz referência à centralidade dos laços também chamados de primários para a confecção da ordem política. Muito longe dos consensos de um liberalismo como o de Hobbes, que deduzia da necessidade de abandono do "estado de natureza" uma visão da cidadania e do estado civil como artificialidades, produtos do engenho humano e de sua capacidade de pactuar (skinNER, 1999; вовBIO, 1991), a representação alencariana buscava grande parte de seu formato e de seu funcionamento nos laços primários 
Lima, C. A. M. Iracema vota. Fiç̧ão, Política e História em José de Alencar.

Revista Letras,

Curitiba, n. 94 p. 142-155, jun./dez. 2016. ISSN 2236-0999 da vida social do face a face. Não se limitava a esses laços, mas demandava-os para empoderar e, por assim dizer, energizar os civilizadores que depois deveriam voltar-se de alguma forma contra aqueles laços primários (que chegou a chamar de "fezes locais", como em alencar, 1991, p. 130).

As experiências monárquicas de voto distrital (os "círculos" imperiais) receberam fortíssimas críticas de Alencar. É curioso que, conceituando-as corretamente a partir de seu princípio majoritário, criticava-o exatamente por considerar o voto distrital um vetor da "tirania da multidão", expressão que usava tanto para o que acontecia no interior dos distritos uninominais, quanto para os parlamentos unipartidários que a política imperial às vezes formava (ALENCAR, 1991, p. 14). Essa ideia de contenção da "ditadura das maiorias" era e é própria dos sistemas políticos como o dos Estados Unidos. Só que sistemas como esses costumam estar ligados à organização distrital da representação. Ainda assim, escreveu quanto à experiência norte-americana que a "maioria ali é onipotente e por conseguinte déspota” (alenCAR, 1991, p. 15). Uma possibilidade de interpretação desses deslocamentos é a de que a "tirania" que Alencar julgava perigosa era a da "multidão" local. Tratava-se, ainda, do registro da "nacionalização". Outra possibilidade reside em sua definição de "monarquia representativa”. Enxergava nelas, inclusive na Inglaterra, restrições às maiorias, criando governos minoritários. Mas estes, exatamente porque minoritários, tornar-se-iam prudentes, evitando exasperar maiorias. Nessas situações, ninguém seria tirano (ALENCAR, 1991, p. 17). É possível que Alencar tivesse em vista um conhecido e frequente efeito dos sistemas majoritários: o descasamento entre "voto popular" e composição efetiva do órgão legislativo, tendo enxergado isso na Inglaterra centralista, mas não na multiplicidade federalista norte-americana. Mas o significativo é sua preocupação com a "totalidade", que deve comportar minorias, ou até mesmo ser governada por elas.

No Império brasileiro, estava em vigência um sistema de múltiplas exclusões (antecipa-se que Alencar não julgava efetivas essas exclusões). Escravos estavam fora do sistema político. Quanto a libertos, a confusão era enorme, inclusive na Constituição, especialmente se eles fossem africanos. Embora ninguém escrevesse sobre as mulheres, algumas das quais grandes proprietárias, elas eram excluídas por um consenso patriarcal subjacente, estabelecido ao redor da independência teórica dos chefes de domicílio. Além disso, a busca de autonomia em termos patriarcais excluía os que não fossem chefes de fogo ou que estivessem explicitamente sujeitados a autoridades (os então chamados filhos-família, religiosos regulares, soldados). A renda anual separava cidadãos ativos e passivos.

A exclusão segundo a renda operava em cadeia. Um cidadão ativo precisava possuir rendimento de cem mil réis (a partir de 1846, duzentos mil réis) para votar em primeiro grau, ou seja, para votar nos eleitores, que precisavam ter o dobro (os cem mil réis dos votantes não constituíam patamar tão alto assim) ${ }^{2}$.

2 Em 1826, em São Paulo, se hipotéticas 15 pessoas habitassem um único domicílio, produzis- 
Lima, C. A. M. Iracema vota. Ficção, Política e História em José de Alencar.
Revista Letras,

Curitiba, n. 94 p. 142-155, jun./dez. 2016. ISSN 2236-0999
Eleitores votavam em deputados, que precisavam ter o dobro da renda mínima dos primeiros, e em senadores vitalícios, que necessitavam ter o quádruplo.

Cada momento de exclusão era visto pelo Autor como o estabelecimento de um vínculo de representação. Em outras palavras, uma pessoa que não possuísse renda de cem mil réis não era excluída pelos tinham aquela soma. Era representada por eles.

Além desses vínculos entre cidadãos ativos e passivos e da aludida concepção a respeito da representação exercida pelo imperador, a teoria dos "representantes naturais" de Alencar era muito significativa a respeito dessas concepções. Era por meio deles que Iracema votava. Gênero, idade, moléstia e "outros impedimentos" (a pobreza extrema e a escravidão eram os candidatos preferenciais para preencher essa lacuna) "inabilitam certas pessoas para o exercício próprio ou direto da soberania" (alENCAR, 1991, pp. 90-91). Essas pessoas, como "ficam sujeitas a seu chefe ou representante civil", "por seu órgão devem exercer os direitos que lhes competem". Desse modo, todos, simplesmente todos votavam: "não há, não pode haver um ente racional, unido por título de origem ou de adoção a qualquer estado que não participe de uma fração correspondente de soberania”. Sem essa espécie de representação é que haveria "despotismo do forte sobre o fraco", não importando a aparência de exclusão que ela pudesse ter aos olhos de observadores futuros (ALENCAR, 1991, p. 80).

O vínculo entre representante e representado seria análogo e compartilharia legitimidade com aquele entre os incluídos na franquia eleitoral e aqueles dela excluídos. Essa exclusão, ao invés de expulsão ou separação, constituiria vínculo, representação. A "incapacidade" não exclui dos direitos políticos. Ela "determina apenas o modo de ação, o exercício" (ALENCAR, 1991, p. 81), da mesma forma que na esfera civil (isto é, nas questões cíveis da família, da propriedade etc.). Como na relação entre representante e representado, as ficções de escolha racional, contrato ou coisa semelhante estavam descartadas de antemão. $\mathrm{O}$ vínculo podia vir de muitos lugares, sendo na verdade bastante improvável para Alencar que ele pudesse provir desse cortejo de transparências.

Emergia assim a coronelística figura do "cidadão representante nato" (ALENCAR, 1991, p. 82). Mesmo rejeitando os exageros censitários que enxergava no sistema vigente, que chamava de "sistema restritivo", Alencar não defendia a "universalidade do voto", pois ela, ao invés de "vínculo", produziria "onipotência da maioria" (alenCAR, 1991, p. 83).

O "sistema restritivo", aliás, teria entre seus piores defeitos o de negar "representantes naturais aos incapazes políticos" (alencar, 1991, p. 83). De certa

sem apenas farinha de mandioca e consumissem toda a farinha produzida (e apenas ela), o cabeça desse fogo poderia, mesmo sem jamais ter visto uma peça de dinheiro amoedado, declarar renda de cem mil réis e tornar-se cidadão ativo. Não precisaria nem mesmo ser alfabetizado. Levam-se em conta os preços do alqueire de farinha de mandioca expostos em CABRAL, 2009, p. 47. Usa-se também o patamar de dez alqueires anuais de farinha de mandioca por pessoa como parâmetro das necessidades alimentares (schwartz, 2001, cap. 4). 
Lima, C. A. M. Iracema vota. Ficção, Política e História em José de Alencar. forma, trava-se de "meia gravidez": ausência de censo seria tirania da maioria; censo muito alto deixaria de ser vínculo, tornando-se mecanismo de exclusão. Alencar, dessa forma, preferia uma calibragem do censo eleitoral (ALENCAR, 1991, p. 92).

O Autor acrescentava mais dois tipos de vínculo àqueles já mencionados (o que fazia o imperador representar a nação, o que ligava os representantes aos representados e o que ligava os representantes naturais aos seus incapacitados). Esses vínculos restantes eram o da eleição indireta de parlamentares (ALENCAR, 1991, p. 102-103), conforme o sistema de dois graus vigente durante a maior parte do período imperial, e o voto por procuração (ALENCAR, 1991, p. 127). Os dois constituíam defesa aberta por Alencar das relações de dependência pessoal, mas sua utilidade não residia na comemoração de coronelismos e clientelismos. Antes, o Autor era bem claro sobre o que o segundo grau deveria fazer com as energias acumuladas através de seus vínculos com o primeiro (o dos meros votantes): no segundo grau (o dos eleitores), "a representação deve ter a maior latitude que o país e a população comportem; só deste modo ela conseguirá nacionalizar-se, depurando-se das fezes locais” (ALENCAR, 1991, p. 130). É difícil imaginar expressões mais evidentes para comunicar uma percepção acerca dos ambientes locais brasileiros, entre os quais o mundo de origem de Iracema.

\section{Considerações finais}

De certa forma, a concepção alencariana da representação política aponta para uma espécie estranha de realismo político, qual seja aquela dos românticos, entendendo-se por tal expressão não exatamente o estilo, mas antes uma visão da sociedade, da cultura e especialmente da política, visão essa própria desses meados do século xIx. A aparente contradição entre a atitude dos românticos e a afirmação feita acima sobre um realismo duro se resolve através da lembrança de sua descrença em relação às fórmulas abstratas do cogito cartesiano. Isso os levava, frequentemente, a ancorar suas formulações políticas na história e em um funcionamento da vida social que julgavam efetivo. Talvez por isso, Wanderley Guilherme dos Santos, tremendo intérprete de Alencar (santos, 1987, p. 12-27; sANTos, 1991), juntou em um mesmo trabalho o elogio da sensibilidade romântica e sua (assim como de Robert Dahl) "definição minimalista de democracia" (santos, 1998). Do mesmo modo que Alencar, Santos entende representatividade como um "vínculo que une eleitores e eleitos" (santos, 1987, p. 37), sem necessariamente demandar a figura - inacreditável para românticos oitocentistas - do indivíduo que, dotado de uma razão abstrata, conheceria de maneira transparente seus interesses e demandas e escolheria, em meio a manifestações muito claras e transparentes de opiniões, os mais verazes representantes. Aquele vínculo é pouco, mas é melhor que nada e, em ambiente de liberalização e competição, tende a tornar-se crescentemente veraz e racional. 
Lima, C. A. M. Iracema vota. Fiç̧ão, Política e História em José de Alencar.

Em Alencar, havia tensão entre a necessidade de atenção aos ambientes locais, de um lado, e a perspectiva de "nacionalização", de outro lado. Essa nacionalização, além disso, também era marcada por tensões, nesse caso entre a particularidade de uma identidade nacional e uma visão universal, ligada ao projeto de "civilização".

No texto, essas tensões eram mantidas, sendo recorrentes as iniciativas de Alencar para fazer com que elas se resolvessem na direção da universalidade do projeto civilizador, no sentido de organizar instituições que aproximassem o país dos comportamentos vistos como desejáveis a partir de um padrão universal e autoritário. A ideia era mobilizar, através da representação proporcional, as "fezes locais" do "exotismo" a fim de superar este último. A questão era o caminho para chegar aí. Como em quase todos os Romantismos políticos conservadores, a estrada para tal não poderia passar por acontecimentos súbitos, interrupções da História, reformismos autoritários de tipo novo, revoluções ou o estabelecimento de pactos que originassem um "novo começo". Manifestava-se quanto a isso a perspectiva, comum às elites políticas imperiais, de que uma formulação institucional muito sofisticada poderia substituir e reformar forças e tendências históricas. ${ }^{3}$

Cada via nacional deveria ser específica, identificada, histórica. Disso resultava a centralidade do vínculo. Ele, embora fosse um dos aspectos derivado do exotismo, viria a permitir, no século xıx, a permanência de um liame apto a ser usado para guiar a construção da representação. Identidade, história e mundo local propiciariam essa ligação entre os agentes, mas não padrões de comportamento e de organização da sociedade. Quanto a esse ponto, romance e reflexão política parecem ter tido uma espécie de relação de colaboração, dialogando como testes alternativos de uma mesma projeção histórica e social. Literatura e ensaio, mais que espelhos da vida social, mais que projetos de sociedade, teriam como finalidade permitir a elaboração estratégica. Nos dois tipos de trabalho, Alencar parecia estar elaborando o "como". O orgânico local e exótico era rechaçado. Alencar parecia só querer dele o mecanismo que permitisse a montagem da "substância nacional", que não se confundia com ele, mas cuja constituição podia aproveitar-se dos liames entre agentes que ele, sim, comportava. Era por fornecer essa ferramenta estratégica que o passado histórico estava vivo. “O navio é que faz o oficial” (costa, 2014, p. 134, 160, 186, 310). 
Lima, C. A. M.

Iracema vota.

Ficção, Política e

História em José de Alencar.

ALENCAR, J. de. Systema representativo. In: SANTOS, W. G. dos (org.). Dois escritos democráticos de José de Alencar. Rio de Janeiro: Ed. da UFRJ, 1991. Facsímile da $1^{\mathrm{a}}$ ed., de 1868.

BLAKE, S. Diccionario Bibliographico Brazileiro. Brasília: Conselho Federal de Cultura, 1970. Fac-símile da ed. de 1899.

BOBBIO, N. Thomas Hobbes. Rio de Janeiro: Campus, 1991.

BOSI, A. Dialética da colonização. São Paulo: Companhia das Letras, 1992.

.O teatro político nas crônicas de Machado de Assis. Revista Brasileira, Rio de Janeiro, n. 41, p.37-75, 2004.

CABRAL, J. A. T. A estatística da imperial província de São Paulo com várias anotações do tenente-coronel José Antônio Teixeira Cabral, membro da mesma estatística. Tomo 10 1827. São Paulo: Ed. da Universidade de São Paulo, 2009. Fac-símile do manuscrito; ed. de Cristina Antunes.

CANDIDO, A. Iniciação à Literatura Brasileira (resumo para principiantes). São Paulo: Humanitas, 1999.

CARVALHO, J. M. de. Radicalismo e Republicanismo. In: CARVALHO, J; M; NEVES, L. M. B. P. das (org.). Repensando o Brasil do oitocentos. Cidadania, política e liberdade. Rio de Janeiro: Civilização Brasileira, 2009. p. 19-48

COSTA, Hilton. O navio, os oficiais e os marinheiros: as teorias raciais e a reforma eleitoral de 1881. Tese (Doutorado em História), Programa de PósGraduação em História, Universidade Federal do Paraná, Curitiba, 2014

GIL, F. O caráter pendular do herói brasileiro. Literatura e sociedade. São Paulo, n. 13, p. 132-151, 2010.

A presença do romance na "Formação da literatura brasileira". O eixo e a roda. Belo Horizonte, v. 20, n. 1, p. 51-68, 2011.

MARSHALL, T. H. Cidadania, classe social e status. Rio de Janeiro: Zahar Editores, 1967.

MARTINS, E. V. A imagem do sertão em José de Alencar. Dissertação (Mestrado em Teoria Literária) - Instituto de Estudos da Linguagem, Universidade Estadual de Campinas, Campinas, 1997.

PELOGGIO, M. José de Alencar e as visões de Brasil. Tese (Doutorado em Letras, área de concentração Literatura Comparada) - Curso de Pós-Graduação em Letras, Universidade Federal Fluminense, Niterói, 2006.

SANTOS, W. G dos. A anomalia democrática: adolescência e romantismo na história política. Revista Brasileira de Ciências Sociais, São Paulo, v. 13, n. 36, sem paginação, 1998. 
Lima, C. A. M. Iracema vota. Ficção, Política e História em José de Alencar.
. Crise e castigo. Partidos e generais na politica brasileira. São Paulo: Vértice; Rio de Janeiro: IUPERJ, 1987.

- A teoria da democracia proporcional de José de Alencar. In: (org.). Dois escritos democráticos de José de Alencar. Rio de Janeiro: Ed. da UFRJ, 1991, p. 9-56.

SCHEIDT, D. Nacionalismo e ambivalência em "O Sertanejo", de José de Alencar. Uniletras, Ponta Grossa, v. 32, n. 2, p. 325-338, 2010.

SCHWARTZ, S. B. Escravos, roceiros e rebeldes. Bauru: Edusc, 2001.

SILVA, A. M. J. F. da. Tavares Bastos: biografia do liberalismo brasileiro. Tese (Doutorado em Ciências Humanas: Ciência Política) - Instituto Universitário de Pesquisas do Rio de Janeiro, Rio de Janeiro, 2005

SKINNER, Q. Razão e retórica na filosofia politica de Hobbes. São Paulo: UNESP, 1999.

SOUSA, C. H. M. R. de. A imagologia no Brasil: primeira tentativa de sistematização. Revista Brasileira de Literatura Comparada, São Paulo, n. 14, p. 37-55, 2009.

VASCONCELOS, S. G. T. Sentidos do demoníaco em José de Alencar. Itha do Desterro, Florianópolis, n. 62, p. 271-292, 2012.

WEINHARDT, M. Considerações sobre o romance histórico. Revista Letras, Curitiba, n. 43, p. 49-59, 1994.

Submetido em 16/9/2016

Aceito em 24/9/2016 